\title{
THE INFLUENCE OF SUPPLY-RELATED CHARACTERISTICS ON GENERAL PRACTITIONERS' WORKLOAD
}

\author{
Peter P. Groenewegen ${ }^{1}$ and Jack B. F. Hutten ${ }^{2}$ \\ 'Netherlands Institute of Primary Health Care-NIVEL, P.O. Box 1568, 3500 BN Utrecht, The Netherlands \\ and ${ }^{2}$ Interuniversity Centre for Social Science Theory and Methodology, Utrecht University, \\ The Netherlands
}

\begin{abstract}
The workload of general practitioners (GPs) is usually defined in terms of the number of hours worked (divided in time spent on different practice tasks), rates of contact (office consultation and home visit rates) and length of consultations. They are influenced by two groups of factors: demand-related influences and supply-related influences. Demand-related influences refer to the list sizes of GPs and the composition of the practice population. Supply-related influences refer to the way GPs themselves manage their workload. In this article the relative influence of demand-and supply-related variables on the workload of Dutch GPs is assessed.

The data for this analysis has been collected as part of the Dutch National Survey of Morbidity and Interventions in General Practice. We draw on four data sources: a three months recording of all contacts between GPs and their patients, a census of the practice population of the GPs, a mailed questionnaire among GPs and a one week diary kept by the GPs. The population consists of 168 GPs.

The number of hours spent by GPs on practice activities is mainly determined by demand-related characteristics. List size and the percentage of elderly on the list are positively related to the time spent on direct patient care. Running a free flow consultation hour is the only factor on the supply side with an additional effect. GPs supervising a trainee and those with a larger percentage of elderly and publicly insured patients on their list spent more hours on other activities such as practice administration, deliberation and reading medical literature.

List size and the percentage of elderly on the list have a negative influence on the office contact rate, while the percentage of low educated patients on the list and the number of practice secretaries per GP have a positive impact. Furthermore, GPs without a free flow consultation hour and those working in health centres tend to have smaller office contact rate than the others. Home visit rates are smaller when the practice secretaries provide a higher percentage of consultations in the practice, in single handed practices and in the case of female GPs. However, the percentage of elderly on the list is the main determinant of the home visit rate. The average length of consultations is not substantially affected by either supply- or demand-related characteristics.
\end{abstract}

Key words -workload, practice organization, general practice, The Netherlands

\section{INTRODUCTION}

Research on the workload of GPs is motivated by the debate on the payment system of GPs on the one hand and by concerns about implications of workload variations for the content and quality of care on the other hand [1]. It is e.g. argued that a 'fair' remuneration system must reflect differences in workload: GPs with a higher workload should have a higher income than those with a smaller workload [2]. Moreover, workload is assumed to influence the performances of GPs in their daily practice. A higher workload indicates that less time is available for each patient which might affect the quality of care $[3,4]$.

The total workload of GPs is generated from two sources: the demand for care by patients (demand related part) and other practice activities (supply related part). The first part refers to the number of consultations handled by the GP and the time spent on direct patient care. Other practice activities are divided into practice organization (practice adminis- tration, deliberation with practice secretaries or colleagues) and medical professional activities such as participation in refresher courses, peer review and reading medical literature.

Both parts are influenced by factors situated at the demand and supply side. The 'demand-led character' of general practice is studied by Calnan and Butler [5]. They used list size as the indicator of demand. A small positive relation is found between list size and workload. Groenewegen et al. extended this analysis by adding other indicators at the demand side, viz. indicators of the composition of the practice population [2]. Overall, the variation in workload indicators explained by demand-related variables increases when indicators of the composition of the practice population are added to the influence of list size as such.

This is, however, still only one side of the coin. On the other side GPs in The Netherlands, like in the U.K., work mainly in independent practice. They have a contract with the public health insurance 
funds to treat the publicly insured patients on their list. The independent character of general practice gives them freedom to run their practice as they prefer. This implies that they make their own decisions about the allocation of their time and the management of their practice. GPs themselves have some influence on the level of their workload by the delegation of consultations to other workers in the practice or through the organization of their practice, e.g. through their appointment system. It is therefore reasonable to suppose that both demand-related and supply-related variables influence the workload of GPs. The aim of this paper is to find out to what extent supply-related variables have an additional influence on the workload of GPs.

\section{BACKGROUND AND RESEARCH QUESTIONS}

Concerns regarding a 'fair' payment system and the quality of care in general practice are the main backgrounds to study the workload of GPs. Dutch GPs are partly paid by capitation. That is, for each publicly insured patient on their list GPs receive a fixed amount of money, irrespective of the number of services they render. Capitation fees are not differentiated according to the age of the patient, like they are in the U.K. and Italy [6]. Publicly insured patients are approx. $65 \%$ of the Dutch population and each GP has a mix of publicly and privately insured patients; the latter pay their GP a fee for each consultation.

Payment systems might be analysed from two different angles. The first is the way payment systems, as instruments of health policy, influence the behaviour of physicians. From this point of view, the assumption of capitation payment might be that physicians invest in their patients' health by providing preventive care to decrease future workload. The second angle looks at the payment system from the point of view of the relation between payment level and current workload or the principle of rewards according to effort. It is from the latter angle that we look at the payment system in this article. From this point of view the assumption behind a flat capitation fee is that all patients require more or less the same amount of work from the GP. Therefore, list size is, by implication, seen as the main determinant of workload. But, is this really so and to what extent does list size determine workload? Not all patients require the same amount of care. Research in health services utilization shows that some groups in the population use more services than others and if these groups would be unequally distributed across practices, an equally large patient list might generate a different workload depending on the composition of the practice population. Differences in income in a capitation system would be justified if list size is indeed the major determinant of workload.

The relation between list size on the one hand and the content and quality of care on the other hand is an important background to study the workload of
GPs. One of the policy measures to increase the quality of care in general practice is the reduction of the list sizes of GPs. This also assumes that list size is an important determinant of the workload of GPs. However, not only list size seems to be relevant but also the way the GPs allocate the available amount of time. A reduction of the number of patients on the lists does not necessarily mean that GPs spend more time on direct patient care: the extra available time can also be spent on other practice activities or leisure time [3]. So, also regarding the relation between workload and the performance of the GPs in daily practice, it is important to investigate the influence of all possible factors on the workload of GPs.

In an earlier paper [2] we have analysed the relative influence of list size and composition of the practice on workload of GPs. List size turned out to be the most important determinant of the total number of hours worked and of the number of hours spent on direct patient care. Practice composition is the most important determinant of the consultation rates, mainly of the home visit rate, of the number of hours spent in non-patient related activities and of the length of consultations. The amount of variance in workload explained by demand-related variables, i.e. list size and practice composition, is highest for the number of hours spent on direct patient care. Still, only half of the variance in hours in direct patient care is explained by demand-related variables. For the other indicators of workload, variance explained by demand-related variables is lower. Hence enough room is left for supply-related variables to exert their influence.

Three types of supply-related factors can be distinguished. Firstly, personal characteristics of the GP; especially gender and age are discussed in the literature. Female GPs have been found to have a lower workload, but also a smaller personal list size [7]. Age of the GP is not related to workload [7], but younger GPs have smaller list sizes suggesting that more experienced GPs can easily cope with a larger potential workload [8]. The second type of supply-related factors are the organizational aspects of the practice that increase or decrease the possibilities to manage a certain amount of demand for care by the patients. Single handed practices have been found to have higher consultation rates and longer consultations [7]. Larger partnerships provide the opportunity to structure the workload $[9,10]$ through the appointment system and a good deputizing service in evening hours and weekends [11]. Task delegation to a practice secretary is a potential time saver [12].

Thirdly, the involvement of GPs in different kinds of activities can be mentioned. Certain GPs are involved in specific activities that increase their workload in terms of hours worked. Other activities outside general practice, such as a teaching job at medical school, have to be left out when analysing workload in general practice. However, having a trainee in one's practice, and running a dispensary or 
doing home deliveries-mainly in rural areas among Dutch GPs-are activities that might increase workload.

Against this background our research question is whether these groups of supply-related variables increase or decrease the workload of GPs, given the influence of demand-related variables. For those supply-related variables that indicate extra activities, we expect to find a positive influence on the workload of GPs. The interpretation is that GPs who engage in extra activities have a higher workload than would be expected on the basis of their list size and composition of practice. For those supply-related variables that indicate the possibilities to manage workload, we expect to find a negative relation. The interpretation is that GPs who have more possibilities to manage the demand of care in their practice, have a lower workload than would be expected on the basis of their list size and composition of practice.

\section{DATA AND METHODS}

The study presented here is part of a large project, the National Survey of Morbidity and Interventions in General Practice [13]. Central to this project is a three month recording of all contacts of 161 general practitioners (and their trainees, locums and assistants) in the Netherlands. In this article data on the 161 independent GPs and 7 permanent locums/ assistant GPs are analysed.

Selection of participating GPs is based on a stratified (according to region, urbanization and distance to a general hospital), random sample. Next to the 98 randomly selected GPs five volunteering GPs and 58 GPs who were partners of these originally selected GPs participated. Data recorded include patient characteristics, characteristics of the consultation (e.g. first or repeat consultation, length of consultation, time of the day), complaints of the patient, diagnosis, and intervention (diagnostic services, treatment, prescriptions, referral). For all practices $(N=103)$ an age/sex register has been set up to be able to relate the contacts to the practice population. This register contains information about 335.000 patients. Out of the participating general practitioners $155 \mathrm{kept}$ a detailed diary covering $24 \mathrm{hr}$ a day during one week (including the weekend) within the three months recording period. Non-response analysis shows no main differences between the GPs who completed the diary and all participating GPs in the study. Comparison to the total population of GPs in the Netherlands, younger GPs, female GPs and GPs working in partnerships are over-represented. This means that our data are not fully representative for all Dutch GPs. However, this does not affect the studied relations between the demand- and supply-related factors on the one hand and workload of GPs on the other hand.

\section{Dependent Variables}

In the literature different indicators of workload are used [1]. They can be divided in three groups: indicators based on rates of contact of patients, indicators based on the time GPs spent on different activities and the average length of consultations. We will use indicators from each of these groups.

\section{(a) Rates of contact}

The number of contacts, during the three months of registration, divided by the personal list size of the GP, expresses the relative workload, given the size of the practice population. Contacts can be handled by the practice secretaries or by the GPs themselves. It is also important to distinguish between office consultations and home visits of GPs. Furthermore, both patients and GPs can be the initiator of the consultation. If the relative number of contacts initiated by patients is larger, the workload generated through the practice population will be larger. Therefore, four different kind of contact rates will be used.

- Total contact rate: all contacts in the practice, handled by GP or practice secretary;

-office contact rate: all office consultations handled by the GP.

-home visit rate: all home visits conducted by the GP;

-patient initiated contact rate: all contacts that, according to the GP, were initiated by the patients themselves

Contacts of trainees and temporary locums or assistant GPs were added to the contacts of their principal GP because they had no personal lists.

\section{(b) Time spent in practice activities}

The diaries were used to compute the time GPs spent in practice. Hours on call were only taken into account as far as they included actual work. Inclusion of all hours on duty, irrespective of actual practice activities, would do justice to an important aspect of workload of GPs. On the other hand, this would make a comparative analysis of the relation between list size and hours worked difficult. Large differences in the number of hours worked could be caused by the fact that some GPs were on duty during the week they kept the diary, while others were not. Furthermore; a distinction was made between two groups of activities namely direct patient care and other activities such as practice administration, education and consultations with colleagues.

\section{(c) Average length of consultations}

The GPs reported the actual length of each consultation, in minutes, on the registration form. To control for differences in travelling time involved in home visits, we have computed the average length of office consultations only. 


\section{Independent Variables}

The independent variables are list size, aspects of the practice composition and supply-related variables.

\section{(a) List size}

The total number of patients per practice was established through the patient register that was set up for each practice. This includes privately as well as publicly insured patients. The practice list size was transformed into an indicator of the personal list size. In the case of single handed practices personal list size equals practice list size. Patients in partnerships or health care centres were asked which GP they usually visit. Patients who did not report one particular GP were distributed over the partners according to their full-time equivalents of involvement in the practice, established at the beginning of the registration period. Trainees and temporary locums or assistants have not been included in the measurement of personal list size. Permanent assistant GPs were treated in the same way as partners, i.e. they have been assigned a personal list size according to full-time equivalents of involvement in the practice.

\section{(b) Practice composition}

Practice composition is measured by means of the percentage of certain patient groups on the personal lists of the GPs. According to earlier research [1], the following patient groups need to be considered: women, elderly people (over 75 years of age), young children (under 5 years of age), publicly insured patients, unemployed people, people with a foreign nationality and low educated people (people over 25 years of age with primary education only). Besides, degree of urbanization is included as indicator for the practice composition [14].

\section{(c) Supply-related variables}

The factors situated on the 'supply-side' are already discussed in the introduction. The related variables are:

\section{(1) GP characteristics:}

-Practice experience (number of years in practice);

-GP's gender $(0=$ female, $1=$ male $)$.

\section{(2) Organizational aspects:}

-rota services not only for the weekends, but also for evening hours on weekdays $(0=$ no, $1=$ yes);

-operating free flow consultation hours, next to an appointment system $(0=$ no, $1=$ yes $)$;

-mode of practice; two dummy variables are included in the analyses: single handed practice $(0=$ no, $1=$ yes $)$ and health centre $(0=$ no, $1=$ yes $)$;

- number of practice secretaries per GP in the practice; -range of activities usually delegated to practice secretaries: a scale of 13 items is used (Cronbach's $\alpha=0.79$ ) [15];

- proportion of consultations actually handled by practice secretaries.

\section{(3) Involvement in specific activities:}

$$
\begin{aligned}
& \text { - doing home deliveries }(0=\text { no, } 1=\text { yes }) \text {; } \\
& \text { - having a trainee in the practice }(0=\text { no, } \\
& 1=\text { yes); } \\
& \text {-running a dispensary for pharmaceutical pre- } \\
& \text { scriptives }(0=\text { no, } 1=\text { yes). }
\end{aligned}
$$

To analyse the influence of the supply-related variables on the indicators of workload, we will start with a simple description of the means of the workload indicators for categories of the supply-related variables. Next the zero-order Pearson correlations between the supply-related variables on the one hand and between supply- and demand-related factors on the other hand will be described. Descriptive statistics of the dependent variables have been reported in an earlier article [2].

The relative influences of demand- and supplyrelated variables on indicators of workload are assessed in a two-step multiple regression analysis. In the first step demand-related variables are included in the equation. In the second step supply-related variables are added. By comparing the explained variances $\left(R^{2}\right)$ of the equations, we can test whether the second equation provides significantly better predictions than the first one. The standardized regression coefficients of the second equation are considered to indicate the variables with the largest contribution.

\section{RESULTS}

Table 1 describes the workload of GPs grouped according to the supply-related variables, without taking into account differences in list size and practice composition. Female GPs have a higher office consultation rate, a lower home visit rate, work less hours in total and in direct patient care and have on the average longer consultations. Less experienced GPs have a higher office contact rate, a higher patient initiated contact rate and longer consultations.

Nearly all Dutch GPs participate in rota services for the weekends and weekday evenings. A few only participate in rota services for the weekends. The latter have a higher total contact and home visit rate.

All GPs in our sample run appointment schemes for their consultations. Almost one third also have free flow consultation hours. They have a higher office consultation rate, a higher patient initiated consultation rate and work more hours per week.

GPs in single handed practice work more hours per week in total and in patient related activities, while GPs in integrated health centres have a lower total consultation rate and a lower home visit rate. 
In practices with more than one practice secretary per GP the home visit rate is lower. The same goes for GPs who delegate a broader range of tasks to their practice secretary. Those GPs whose practice secretaries handle a higher percentage of the consultations, have a higher total contact rate, a lower office contact rate and a lower patient initiated contact rate.

GPs who do home deliveries have a higher total contact rate. Having a trainee in one's practice results in more hours worked in total and in more hours spent in other activities. GPs who run a dispensary have a higher total contact rate, a lower office contact rate, a lower patient initiated contact rate and spent less hours on direct patient care.

The supply-related variables are correlated amongst each other, as shown in Table 2. Female GPs are underrepresented in the group of GPs with more years of experience. This mirrors the increase of the number of female GPs in the past decade [16]. GPs with more years of practice experience more often have a trainee. Female GPs more often work in partnerships and less in single handed practices. They are less often involved in doing home deliveries. No rota services for weekday evenings is associated with working in single handed practices, with doing deliveries and running a dispensary, and with a larger percentage of consultations handled by the practice secretary. Together this refers to the more rural practices.

Running a free flow consultation hour is not related to any of the other supply related variables. GPs in single handed practices have more practice secretaries per GP, but the range of tasks delegated is smaller. GPs in health centres also have more practice secretaries per GP and they also delegate a broader range of activities. On the whole, more practice secretaries per GP coincides with a broader range of activities delegated. GPs who have a trainee delegate a broader range of tasks to the practice secretary. Those who run a dispensary delegate a smaller range of tasks, but a higher percentage of consultations is actually handled by the secretary.

Table 1. Indicators of workload of GPs according to supply-related variables

\begin{tabular}{|c|c|c|c|c|c|c|c|c|c|}
\hline & $\begin{array}{l}\text { Total } \\
\text { contact } \\
\text { rate }\end{array}$ & $\begin{array}{l}\text { Office } \\
\text { contact } \\
\text { rate }\end{array}$ & $\begin{array}{l}\text { Home } \\
\text { visit } \\
\text { rate }\end{array}$ & $\begin{array}{c}\text { Patient } \\
\text { initiated } \\
\text { contact rate }\end{array}$ & $\begin{array}{c}\text { Total } \\
\text { hours worked } \\
\text { per week }\end{array}$ & $\begin{array}{l}\text { Hours spent } \\
\text { in patient } \\
\text { care }\end{array}$ & $\begin{array}{l}\text { Hours spent } \\
\text { in other } \\
\text { activities }\end{array}$ & $\begin{array}{c}\text { Average length } \\
\text { of office } \\
\text { consultations }\end{array}$ & $N$ \\
\hline \multicolumn{10}{|c|}{ No. of years in practice } \\
\hline$<6 \mathrm{yr}$ & 1.26 & 0.68 & 0.14 & 0.62 & 44.8 & 31.6 & 13.1 & 9.20 & 32 \\
\hline$\geqslant 6 \mathrm{yr}$ & 1.17 & $0.61^{*}$ & 0.14 & $0.55^{*}$ & 49.1 & 34.4 & 14.7 & $8.13^{*}$ & 123 \\
\hline \multicolumn{10}{|l|}{ Gender of the GP } \\
\hline Male & 1.18 & 0.61 & 0.15 & 0.55 & 49.4 & 35.2 & 14.2 & 8.23 & 140 \\
\hline Female & 1.21 & $0.67^{*}$ & $0.11^{*}$ & 0.58 & $40.4^{*}$ & $24.8^{*}$ & 15.6 & $9.26^{*}$ & 28 \\
\hline \multicolumn{10}{|c|}{ Rota services evenings } \\
\hline No & 1.45 & 0.56 & 0.20 & 0.47 & 50.3 & 34.8 & 15.4 & 8.63 & 8 \\
\hline Yes & $1.18^{*}$ & 0.62 & $0.14^{*}$ & 0.56 & 48.3 & 33.9 & 14.4 & 8.28 & 150 \\
\hline \multicolumn{10}{|c|}{ Free flou consultations } \\
\hline No & 1.15 & 0.60 & 0.14 & 0.54 & 46.7 & 32.6 & 14.1 & 8.45 & 103 \\
\hline Yes & 1.22 & $0.66^{*}$ & 0.14 & $0.59^{*}$ & $50.4^{*}$ & 35.5 & 15.0 & 8.32 & 65 \\
\hline \multicolumn{10}{|l|}{ Mode of practice } \\
\hline Single handed & 1.19 & 0.60 & 0.15 & 0.55 & 51.3 & 37.9 & 13.4 & 8.33 & 57 \\
\hline Partnership & 1.21 & 0.63 & 0.14 & 0.56 & 46.6 & 31.7 & 14.9 & 8.32 & 93 \\
\hline Health centre & $0.99^{*}$ & 0.62 & $0.09 *$ & 0.54 & $46.5^{*}$ & $31.4^{*}$ & 15.1 & 9.01 & 18 \\
\hline \multicolumn{10}{|c|}{ No. of Practice secretaries per $G P$} \\
\hline$\leqslant 1$ & 1.18 & 0.61 & 0.15 & 0.56 & 48.0 & 33.8 & 14.2 & 8.35 & 119 \\
\hline$>1$ & 1.19 & 0.64 & $0.12 *$ & 0.56 & 48.2 & 33.2 & 15.0 & 8.52 & 49 \\
\hline \multicolumn{10}{|c|}{ Range of activities delegated } \\
\hline$<14$ & 1.22 & 0.61 & 0.16 & 0.55 & 46.5 & 32.4 & 14.2 & 8.09 & 80 \\
\hline$\geqslant 14$ & 1.18 & 0.63 & $0.12^{*}$ & 0.57 & 49.9 & 34.9 & 15.0 & 8.52 & 77 \\
\hline \multicolumn{10}{|c|}{$\%$ of consultations by practice secretaries } \\
\hline$<29$ & 1.06 & 0.65 & 0.15 & 0.60 & 48.4 & 34.0 & 14.4 & 8.43 & 84 \\
\hline$\geqslant 29$ & $1.30^{*}$ & $0.58^{*}$ & 0.13 & $0.51^{*}$ & 47.8 & 33.3 & 14.5 & 8.37 & 84 \\
\hline \multicolumn{10}{|c|}{ Doing home deliveries } \\
\hline No & 1.15 & 0.63 & 0.13 & 0.57 & 47.4 & 33.3 & 14.0 & 8.40 & 107 \\
\hline Yes & $1.30^{*}$ & 0.61 & 0.16 & 0.54 & 49.6 & 34.3 & 15.3 & 8.22 & 53 \\
\hline \multicolumn{10}{|l|}{ Having a trainee } \\
\hline No & 1.20 & 0.63 & 0.14 & 0.57 & 47.2 & 33.8 & 13.4 & 8.37 & 124 \\
\hline Yes & 1.20 & 0.60 & 0.13 & 0.54 & $51.5^{*}$ & 33.6 & $17.9^{*}$ & 8.40 & 35 \\
\hline \multicolumn{10}{|c|}{ Running a dispensary } \\
\hline No & 1.12 & 0.63 & 0.13 & 0.58 & 48.7 & 34.8 & 14.0 & 8.37 & 128 \\
\hline Yes & $1.37^{*}$ & $0.58^{*}$ & 0.16 & $0.50^{*}$ & 46.2 & $30.3^{*}$ & 15.9 & 8.49 & 40 \\
\hline
\end{tabular}


Table 2. Pearson correlations between supply-related factors

\begin{tabular}{|c|c|c|c|c|c|c|c|c|c|c|c|}
\hline & 1 & 2 & 3 & 4 & 5 & 6 & 7 & 8 & 9 & 10 & 11 \\
\hline $\begin{array}{l}\text { 1. No. of years } \\
\text { in practice }\end{array}$ & & & & & & & & & & & \\
\hline 2. Gender of GP (male) & $0.16^{*}$ & & & & & & & & & & \\
\hline $\begin{array}{l}\text { 3. Rotaservices } \\
\text { evenings (yes) }\end{array}$ & -0.15 & -0.09 & & & & & & & & & \\
\hline $\begin{array}{l}\text { 4. Free flow } \\
\text { consultation (yes) }\end{array}$ & -0.04 & 0.03 & 0.01 & & & & & & & & \\
\hline $\begin{array}{l}\text { 5. Single handed } \\
\text { practice (yes) }\end{array}$ & 0.14 & $0.15^{*}$ & $-0.19^{*}$ & 0.02 & & & & & & & \\
\hline 6. Health centres (yes) & -0.05 & 0.05 & 0.08 & -0.04 & $-0.25 * *$ & & & & & & \\
\hline $\begin{array}{l}\text { 7. No. of practice } \\
\text { secretaries per GP }\end{array}$ & -0.03 & $0.22 * *$ & -0.01 & -0.02 & $0.24 * *$ & $0.22 * *$ & & & & & \\
\hline $\begin{array}{l}\text { 8. Range of activities } \\
\text { delegated } \\
\text { 9. } \% \text { of consultations }\end{array}$ & 0.01 & -0.00 & 0.10 & 0.08 & $-0.22^{*}$ & $0.33^{* *}$ & 0.14 & & & & \\
\hline by secretaries & 0.10 & 0.03 & $-0.23 * *$ & -0.01 & 0.02 & -0.14 & $0.21^{* *}$ & 0.01 & & & \\
\hline $\begin{array}{l}\text { 10. Doing home } \\
\text { deliveries (yes) }\end{array}$ & 0.09 & $0.18^{*}$ & $-0.26 * *$ & -0.08 & 0.02 & -0.15 & 0.11 & -0.09 & $0.29^{* *}$ & & \\
\hline 11. Having a & & & & & & & & & & & \\
\hline trainee (yes) & $0.26^{* *}$ & 0.09 & -0.02 & -0.12 & -0.04 & 0.07 & 0.15 & $0.21^{*}$ & 0.12 & -0.02 & \\
\hline $\begin{array}{l}\text { 12. Running a } \\
\text { dispensory (yes) }\end{array}$ & 0.01 & 0.03 & $-0.33^{* *}$ & -0.07 & 0.01 & $-0.19^{*}$ & 0.06 & $-0.27^{* *}$ & $0.46^{* *}$ & $0.42^{* *}$ & -0.13 \\
\hline
\end{tabular}

Significance: $* P<0.05,{ }^{* *} P<0.01$.

These consultations have obviously to do with repeat prescriptions.

Table 3 shows the correlations between supply- and demand-related factors. Male GPs, more experienced GPs (who are more likely to have a trainee in their practice) and GPs working in a single handed practice have more patients on their personal lists. List size is positively related to the number and range of activities of the practice secretaries.

We see that some personal GP characteristics coincide with the composition of their practice population. Older GPs have a larger proportion of elderly (which also coincides with a larger proportion of low educated patients) and a smaller proportion of young children on their personal list and female GPs have relatively more female patients. Besides, female GPs are more likely to work in urban areas.

Doing home deliveries and running a dispensary are almost exclusively activities of GPs in rural areas. Therefore, GPs who run a dispensary have a smaller percentage of patients with a foreign nationality on their personal lists. They also have a smaller percentage of women and unemployed persons in their practice population. Practices in big cities are more likely to participated in a rota system for the evenings. Health centres are more frequently situated in urban areas with a younger population and relatively more patients with a foreign nationality. The personal lists of GPs working in single handed practices contain a higher percentage of elderly.

In a multivariate analysis the influence of the supply-related variables has been assessed, taking the influence of list size and practice composition into account by first running a regression analysis with the demand-related variables only and then adding the supply-related variables (see Table 4). Adding the supply-related variables in the regression equation changes the coefficients of the demand variables only slightly. The influence of list size increases, especially in the explanation of contact rates; the influence of urbanisation disappears in the explanation of the total contact rate. There is a negative relation between personal list size on the one hand and the total contact rate, office contact rate and the patient initiated contact rate on the other hand.

Table 3. Pearson correlations between supply- and demand-related factors

\begin{tabular}{|c|c|c|c|c|c|c|c|c|c|}
\hline & $\begin{array}{l}\text { List } \\
\text { Size }\end{array}$ & $\begin{array}{c}\% \\
\text { Young } \\
\text { children }\end{array}$ & $\begin{array}{c}\% \\
\text { Elderly }\end{array}$ & $\begin{array}{c}\% \\
\text { Women }\end{array}$ & $\begin{array}{c}\% \\
\text { Low } \\
\text { educat }\end{array}$ & $\begin{array}{c}\% \\
\text { Unemployed }\end{array}$ & $\begin{array}{c}\% \\
\text { Foreign }\end{array}$ & $\begin{array}{c}\% \\
\text { Publ. } \\
\text { insured }\end{array}$ & Urbanization \\
\hline No. of years in practice & $0.30^{* *}$ & $-0.38^{* *}$ & $0.16^{*}$ & $-0.17^{*}$ & $0.25 * *$ & -0.01 & 0.03 & -0.01 & -0.10 \\
\hline Gender of GP (male) & $0.50^{* *}$ & -0.04 & 0.07 & $-0.50^{* *}$ & 0.07 & $-0.17^{*}$ & -0.10 & -0.02 & $-0.16^{*}$ \\
\hline Rotaservices evenings (yes) & -0.04 & 0.03 & -0.14 & 0.10 & $-0.31^{* *}$ & 0.06 & 0.03 & -0.05 & $0.21 * *$ \\
\hline Free flow consultation (yes) & -0.01 & 0.00 & -0.01 & 0.09 & 0.03 & 0.07 & $0.17^{*}$ & 0.03 & 0.05 \\
\hline Single handed practice (yes) & $0.20^{* *}$ & $-0.24^{* *}$ & $0.35^{* *}$ & 0.04 & $0.23^{* *}$ & 0.04 & 0.03 & -0.08 & 0.13 \\
\hline Health centres (yes) & -0.04 & $0.24^{* *}$ & $-0.24^{* *}$ & 0.01 & $-0.27 * *$ & -0.07 & $0.32 * *$ & -0.15 & $0.19^{*}$ \\
\hline No. of practice secretaries per GP & $0.30^{* *}$ & $0.20^{* *}$ & -0.12 & -0.05 & -0.03 & -0.08 & 0.08 & -0.02 & $-0.16^{*}$ \\
\hline Range of activities delegated & $0.23^{* *}$ & 0.11 & $-0.27^{* *}$ & 0.08 & $-0.21 * *$ & 0.11 & 0.15 & 0.01 & 0.08 \\
\hline$\%$ of consultations by secretaries & $0.19^{*}$ & -0.10 & 0.12 & $-0.20^{*}$ & $0.35^{* *}$ & -0.03 & $-0.21^{* *}$ & $0.18^{*}$ & $-0.39^{* *}$ \\
\hline Doing home deliveries (yes) & 0.09 & 0.03 & 0.06 & $-0.21 * *$ & 0.06 & -0.11 & -0.09 & -0.02 & $-0.23 * *$ \\
\hline Having a trainee (yes) & $0.20^{* *}$ & -0.03 & -0.11 & -0.05 & 0.09 & 0.08 & 0.01 & 0.12 & -0.10 \\
\hline Running a dispensory (yes) & $-0.16^{*}$ & $0.15^{*}$ & 0.08 & $-0.27 * *$ & $0.16^{*}$ & $-0.31^{* *}$ & $-0.40^{* *}$ & -0.08 & $-0.45^{* *}$ \\
\hline
\end{tabular}

Significance: $* P<0.05 ; * * P<0.01$. 
The influence of supply-related characteristics on GPs' workload

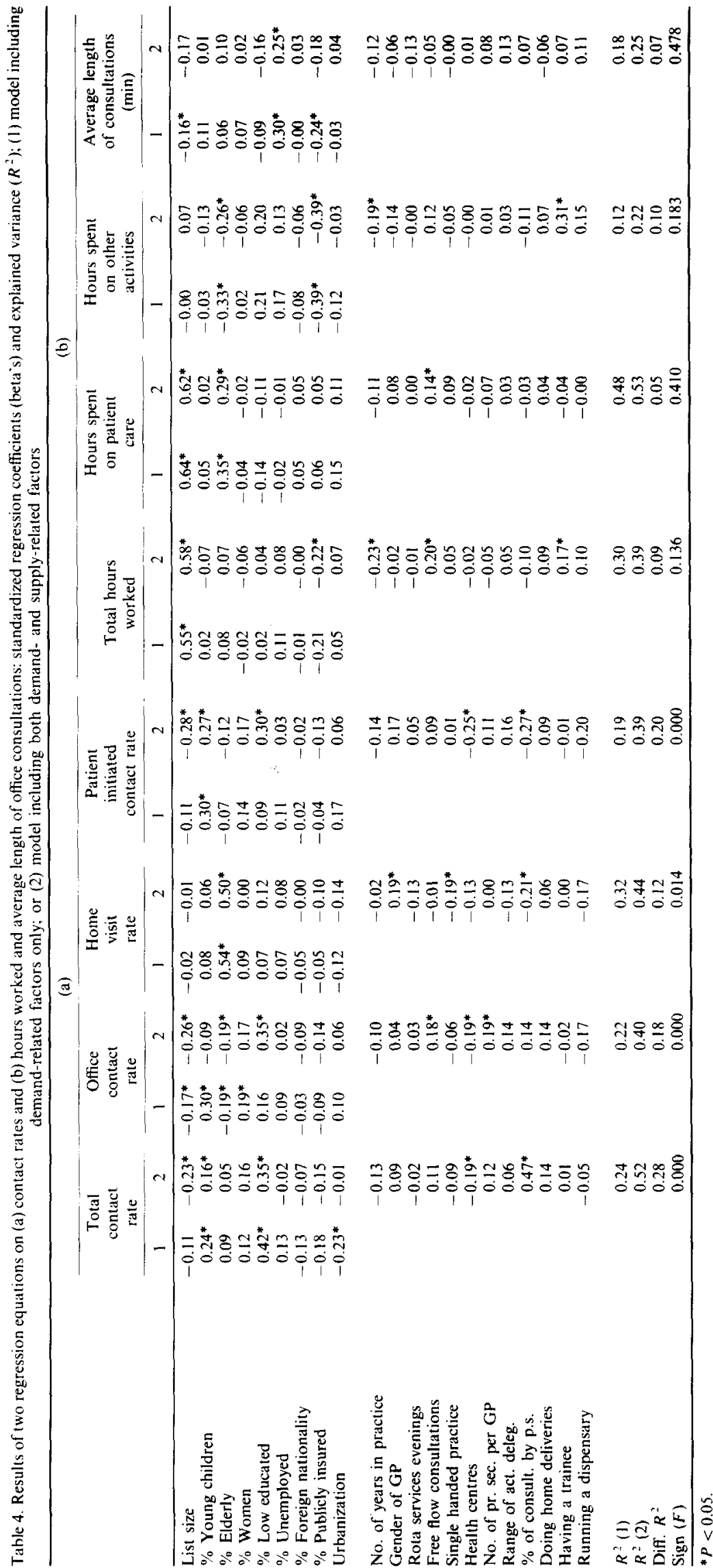


With regard to GPs' gender only the regression coefficient of the relation with the home visit rate is significant. The original, bivariate differences (see Table 1)-female GPs have a higher office contact rate, work less hours and have longer consultationsdisappear in a multivariate analysis controlled for demand-related and other supply-related variables. Only the home visit rate remains lower for female GPs. More experienced GPs work less hours per week and spend less time in non-patient related activities. The other bivariate conditions--lower office contact rate, patient initiated contact rate and shorter consultations-disappear.

Controlling for demand-related and other supplyrelated variables, participating in rota services also for the evenings on weekdays is not related to workload. Those who also operate a free flow consultation hour have a higher office consultation rate and work more hours in total and in direct patient care. GPs in single handed practices have a lower home visit rate, although in the bivariate analysis (reported in Table 1) they have a higher home visit rate compared to GPs in health centres. The latter have a lower total contact rate, office consultation rate and patient initiated contact rate, but their home visit rate--which is lower in the bivariate analysis-does not differ significantly from the other practice modes. The variables related to the role of the practice secretaries are not related to the number of hours worked. The availability of practice secretaries is positively related to the office contact rate. When practice secretaries actually handle more consultations, the total contact rate is higher and the home visit rate and the patient initiated contact rate are lower.

Having a trainee results in longer hours in total and in more hours spent on practice organization. Involvement in the other two extra activities-running a dispensary and doing home deliveries-is in the multivariate regression analysis not related to the workload indicators.

Table 4 also shows the coefficients of determination of the regression equation including only demand-related variables, and of the equation also including supply-related variables. Adding the supply-related variables significantly improves the coefficients of determination for the contact rates. Although there is also some improvement in the explained variance of the hours worked and length of consultations, this is not significant.

\section{DISCUSSION}

In this article we have analysed the influence of variables that relate to the GP and his/her practice organization on indicators of workload. The influence of list size and composition of practice (demand related variables) was taken into account. New to the analysis in this paper is first that both demand-related and supply related influences on workload have been studied, and secondary that they have been analysed in a multivariate way, which is important because of the correlations between variables.

We expected to find positive relations between indicators of workload and supply-related variables that indicate extra activities of GPs. This turned out only to be the case for having a trainee, but not for running a dispensary and doing home deliveries. It seems that the higher workload of GPs who run a dispensary is largely met by their practice secretaries, who handle e.g. a large number of contacts concerning repeat prescriptions.

Supply-related variables that indicate possibilities for managing the workload are supposed to be related to a lower workload. GPs who only work with an appointment system have a lower workload compared to those who have free flow consultations as well. Reducing the accessibility of the practice seems to be a rather easy way to regulate one's workload. In this study, having a single handed practice does not coincide with a higher workload: controlling for the other variables single handed GPs have less home visits and do not differ on the other workload variables. Availability of practice secretaries and the actual number of consultations handled by the practice secretary keep the practice accessible (higher total contact rate and office contact rate). These aspects of delegation have no influence on the number of hours worked by GPs.

Gender is the only personal characteristic of GPs related to the home visit rate, while the workload in terms of hours worked of more experienced GPs is lower than of less experienced GPs.

As far as the relative influence of demand- and supply-related characteristics on the workload of GPs is concerned, it is concluded that the number of hours spent by GPs on practice activities is mainly determined by demand-related characteristics (list size and practice composition). The increase of the coefficient of determination after adding supply-related variables is not significant. The rates of contact, however, are more strongly influenced by supply-related characteristics. The average length of consultations is not substantially affected by either supply- or demand-related characteristics.

It may be concluded that the allocation of time by GPs at the general level of working hours and the division between direct patient care and other activities is influenced by aggregate characteristics of the practice population, mainly list size. At the level of consultations aggregate characteristics of neither the practice population nor the organization of practice are of any influence. The length of consultations seems to be more directly influenced by what happens in the consultation, i.e. the combined influence of the complaints presented in the consultations and the actions taken by the GPs. This combined influence could better be studied at the appropriate level of consultations instead of at the aggregate level of average length of consultations. 
The rate of contacts, i.e. the number of contacts divided by the practice population, is influenced by the organization of the practice, and most strongly by the percentage of consultations that is handled by the practice secretary. However, the range of activities delegated to the practice secretary does not have an independent influence on the contact rates. An interpretation of this finding might be that the practice secretary mainly gives administrative support, e.g. in handling repeat prescriptions.

In this article we have conceptualized GPs' workload in terms of hours worked, length of consultations and rates of contact [17]. The relation between list size and allocation of time is by and large comparable between the Netherlands and the U.K., only the relation with the number of hours spent in patient related activities is somewhat stronger in the Netherlands [18]. Although variations between GPs in the number of hours worked are strongly related to list size, the same relation is not as clear at the aggregate level of health care systems. In comparing European countries there is no clear relation between crude estimates of average working hours and density of GPs [6]. In his European study of referrals, Fleming [19] finds a positive relation between the number of consultations per week and the density of GPs. However, after calculating consultation rates the relation disappears [20].

One of the backgrounds of workload studies, as mentioned in the Introduction, are the debates on remuneration. Workload of GPs is mainly studied in health care systems with capitation payment of GPs. In the context of these debates our study shows that differentiating the flat capitation fee that is being used now in the Netherlands would be an improvement. The workload consequences of differences in practice composition would then to some extent be compensated for. However, substantial differences between GPs would remain, especially in the field of contact rates. This could be compensated for by introducing fees per consultation alongside capitation, as is the case in Denmark [21]. This would, however, increase the administrative costs of the system. There is evidence that the introduction of fees per consultation in combination with capitation (and a relatively small portion of fees for separate services within consultations) does not lead to an increased number of consultations [22]. Pure fee for service systems, however, might lead to an increased number of consultations. Fleming's study [19] shows that the health care systems with fee for service payment for GPs are amongst the highest in average number of consultations; also when consultation rates are calculated on the basis of his figures, the fee for service systems rank amongst the highest six countries (out of a total 11 European countries) [23].

The length of consultations does not clearly relate to aggregate characteristics on demand or supply side. However, given the large variation in the average number of consultations per week in Fleming's study, ranging from 220 in the former Federal Republic of Germany to 60 in Norway, average length of consultations will also differ; even if we take into account that total working hours also differ. The average length of consultations in countries with salaried GPs such as Sweden is two to three times as long as in the U.K. and The Netherlands $[18,24]$.

In conclusion we would like to point to the necessity of research into the workload of GPs at two levels. The first is studies into the length of consultations at the lowest level of aggregation; the second is internationally comparative studies on working hours and rates of contacts in a sufficiently large number of countries to disentangle influences of density of GPs, systems of remuneration and other system characteristics.

\section{REFERENCES}

1. Groenewegen P. P. and Hutten J. B. F. Workload and job satisfaction among general practitioners: a review of the literature. Soc. Sci. Med. 32, 111 I, 1991.

2. Groenewegen P. P., Hutten J. B. F. and van der Velden J. List size, composition of practice and general practitioners' workload in the Netherlands. Soc. Sci. Med. 34, 263, 1992.

3. Butler J. R. and Calnan M. Too Many Patients? A Study of the Economy of Time and Standards of Care in General Practice. Aldershot, Avebury, 1987.

4. Howie J. G. R., Porter A. M. D. and Forbes J. F. Quality and the use of time in general practice: widening the discussion. Br. Med. J. 1008, 1989.

5. Calnan $M$. and Butler J. R. The economy of time in general practice: an assessment of the influence of list size. Soc. Sci. Med. 26, 435, 1988.

6. Groenewegen P. P., van der Zee J. and van Haaften R. Remunerating General Practitioners in Western Europe. Aldershot, Avebury, 1991.

7. Wilkin D., Hodgkin P. and Metcalfe D. Factors affecting workload: is received wisdom true? In The Medical Annual, 1986. The Yearbook of General Practice (Edited by Pereira Gray D. J.). Wright, Bristol, 1986.

8. Armstrong D. and Griffin G. A. Patterns of work in general practice in the Bromley Health District. $J . R$. College gen. Practitioners 37, 264, 1987.

9. Branthwaite A. and Ross A. Satisfaction and job stress in general practice. Family Practice 5, 83, 1988.

10. Freeman G. K. Receptionists, appointment systems and continuity of care. J.R. College gen. Practitioners 39, $145,1989$.

11. Bridgstock $M$. General practitioners' organization and estimates of their workload. J.R. College gen. Practitioners 26, suppl.1, 16, 1976.

12. de Haan J. De doktersassistente; delegeren van taken in een huisartspraktijk. Lelystad, Meditekst, 1986.

13. Foets M., van der Velden J, and de Bakker D. Dutch National Survey of General Practice, a Summary of the Survey Design. Utrecht, NIVEL, 1992.

14. The degree of urbanization has been included in the set of demand-related characteristics. Urban dwellers are less well off in terms of health and health related behaviour (compare e.g. Verheij R. De grote-stadspraktijk. Utrecht, NIVEL, 1993; Garretsen H. F. L. and Raat H. Gezondheid in de vier grote steden. Den Haag, Wetenschappeliijke Raad voor het Regeringsbeleid, 1989).

15. Foets M., Stokx L., Hutten J. and Sixma H. De huisartsenquete van de nationale studie: datareductie door schaalconstructie. Utrecht, NIVEL, 1991. 
16. Kortenhoeven D. Vrouwelijke artsen en vestiging als huisarts. Utrecht, Bohn, Scheltema \& Holkema, 1990.

17. The subjective side-how do GPs experience their workload and how is subjective workload related to carrying capacity - has not been studied. Compare Branthwaite and Ross (Ref. [9]); Makin P. J., Rout U. and Cooper C. L. Job satisfaction and occupational stress among general practitioners; a pilot study. $J$. $R$. College gen. Practitioners 38, 303, 1988; Dierendonck D. van, Sixma $\mathbf{H}$. and Groenewegen P. P. De opgebrande huisarts. Medisch Contact 47, 331, 1992.

18. Calnan M., Groenewegen P. P. and Hutten J. B. F. Professional reimbursement and management of time in general practice: an international comparison. Soc. Sci. Med. 35, 209, 1992.

19. Fleming D. M. The European Study of Referrals from Primary to Secondary Care. Thesis Publishers, Amsterdam, 1993.

20. We calculated consultation rates by multiplying the average number of consultations per week by 52 and divided this by the number of inhabitants per GP (as a proxy of list size). Overall there is no clear relation between this proxy of list size and consultation rate. However, the eight countries falling in the range between 1400 and 2100 inhabitants per GP show a slightly positive relation between list size and consultation rate.

21. Flierman H. A. Changing the Payment System of General Practitioners. Utrecht, NIVEL, 1991.

22. Krasnik A., Groenewegen P. P., Pedersen P. A. et al. Changing remuneration systems: effects on activity in general practice. Br. Med. J. 300, 1698, 1990.

23. Sandier, on the basis of only six health sysetms, does not find evidence for a higher number of visits in systems with fee for service payment for GPs. Sandier $S$. Health service utilization and physician income trends. Hlth Care Financing Rev. annual supplement, 33-48, 1989.

24. Andersson S-O. and Mattson B. Length of consultations in general practice in Sweden: views of doctors and patients. Family Practice 6, 130, 1989. 